\title{
Optic Neuritis in a Patient with Seropositive Myelin Oligodendrocyte Glycoprotein Antibody During the Post-COVID-I 9 Period
}

\author{
Lepša Žorić (iD) ${ }^{1,2}$ \\ Isidora Rajović-Mrkić ${ }^{3}$ \\ Emina Čolak ${ }^{4}$ \\ Dijana Mirić ${ }^{5}$ \\ Bojana Kisić ${ }^{5}$ \\ 'Faculty of Medicine, University of \\ Pristina Settled in Kosovska Mitrovica \\ (UPKM), Kosovska Mitrovica, Serbia; \\ ${ }^{2}$ Institute of Ophthalmology, University \\ Clinical Center of Serbia, Belgrade, \\ Serbia; ${ }^{3}$ Ophthalmology Department, \\ Clinical Center of Kosovska Mitrovica, \\ Kosovska Mitrovica, Serbia; ${ }^{4}$ Institute of \\ Medical Biochemistry, Clinical Center of \\ Serbia, Belgrade, Serbia; ${ }^{5}$ Institute of \\ Medical Biochemistry, Faculty of \\ Medicine, University of Priština Settled in \\ Kosovska Mitrovica (UPKM), Kosovska \\ Mitrovica, Serbia
}

\begin{abstract}
Reports of neuro-ophthalmological manifestations and complications in patients with coronavirus disease 19 (COVID-19) are still scarce. The aim of this article is to present optic neuritis, as possible post-infectious manifestation of COVID-19. Four weeks after hospitalization for seropositive coronavirus disease 19 (COVID-19), presented as bilateral bronchopneumonia, with radiology and laboratory findings also pointed to high clinical suspicion to COVID-19, a 63-year-old man developed a headache and subacute and profound visual loss on his right eye. The disease presentation was the right eye papillitis. Inflammatory parameters were normal at the time of hospitalization, and $\operatorname{IgM}$ and $\operatorname{IgG}$ for SARS-CoV-2 were still positive. After corticosteroid pulse therapy, his vision improved significantly and on follow-up visits returned to normal. All laboratory and radiology findings were unremarkable, except for antibodies against SARS-CoV-2 and myelin oligodendrocyte glycoprotein (MOG). We discuss about capacity of SARS-CoV-2 to cause optic neuritis and possible significance of MOG antibodies in similar cases.
\end{abstract}

Keywords: optic neuritis, SARS-CoV-2, MOG antibodies

\section{Introduction}

After the WHO declared the COVID-19 pandemic, in March 2020, the number of the reports of the other organ systems involvement by SARS-CoV-2 virus has increased, aside of, reasonably, the respiratory ones. This was particularly the case for the nervous system. ${ }^{1}$ In contrast, there have been only a handful of clinically significant ophthalmological and neuro-ophthalmological cases. ${ }^{2}$

The nervous system can be affected by SARS-CoV-2 via several mechanisms: directly, by neurotoxic action, when the virus reaches the nervous system by different routes and binds to angiotensin-converting enzyme 2 (ACE2) receptors, cytokine storm with blood-brain barrier disruption and immunological mediation, and by increased blood coagulation and blood clot formations. ${ }^{3}$

Optic neuritis is inflammation of the optic nerve, and it has varied causes. ${ }^{4}$ The usual manifestations are papillitis-anterior neuritis, with visible optic nerve head edema and retrobulbar neuritis, in which signs of inflammation are not visible on the ocular fundus.

Neuro-ophthalmological manifestations are rare in COVID-19. ${ }^{1,5-9}$ Three reports identified connections between SARS-CoV-2 and optic neuritis, with or without spinal or cerebral demyelinating lesions, associated with serum antibodies
Correspondence: Lepša Žorić

Email zoriclepsa@gmail.com 
against myelin oligodendrocyte glycoprotein (MOG). ${ }^{6-8}$ Two cases appeared during symptomatic COVID-19, and one appeared a few weeks after the disease.

MOG is a glycoprotein located on the outermost surface of the myelin surrounding oligodendrocytes. It is found exclusively in the central nervous system (CNS). When antibodies against MOG enter the CNS, they cause MOG antibody disease (MOG-AD), a distinct form of demyelinating disease. The most consistent presentation of the disease is optic neuritis. ${ }^{10}$

In light of the small number of cases of optic nerve inflammation related to COVID-19 and their association with anti-MOG antibodies, we present a case and discuss possible connections.

\section{Case Report}

In July 2020, a 63-year-old man developed fatigue, shortness of breath, dry cough and fever to $38^{\circ} \mathrm{C}$. A chest radiograph revealed bilateral bronchopneumonia, more prominent on the left. Nasopharyngeal swab for the realtime polymerase chain reaction (RT-PCR) test for SARSCoV-2 was negative. However, serology was positive for IgM and IgG antibodies against the virus. His erythrocyte sedimentation rate (ESR) was $75 \mathrm{~mm} / \mathrm{h}, \mathrm{C}$-reactive protein (CRP) was $103.5 \mathrm{mg} / \mathrm{l}$, D dimer was $1281.05 \mathrm{ng} / \mathrm{mL}$, lactate dehydrogenase (LDH) was $505 \mathrm{U} / \mathrm{L}$, and ferritin 1004 $\mathrm{ng} / \mathrm{mL}$. His complete blood count was within normal limits $\left(5.3 \times 10^{9}\right.$ leucocytes, with slight predomination of granulocytes $(84 \%))$. Other biochemical analyses were unremarkable, except for an elevated glucose level (8 mmol/l). His oxygen saturation $\left(\mathrm{SpO}_{2}\right)$ was $92 \%$. Due to high clinical suspicion of COVID 19, he was hospitalized and treated with antibiotics and anticoagulant therapy. His history was positive for arterial hypertension, treated appropriately. Metformin was introduced in his therapy, with additional diabetes mellitus type II diagnosis. Ten days after presentation, he was discharged from the hospital with $\mathrm{SpO}_{2} 96 \%$, improved chest $\mathrm{x}$-ray findings and improved clinical status. His laboratory values returned to normal over the subsequent two weeks. Seven days later, a nasopharyngeal swab was again negative. Viral serology remained positive for $\operatorname{IgM}$ and $\operatorname{IgG}$, and he had lymphopenia (9\%).

Four weeks later, he developed blurred vision in his right eye. Initially, visual acuity was normal, but within a week it decreased to 20/630 (0.03) on the right and remained normal (1.0) on the left eye. He had a small papillary edema on the right fundus. The other ophthalmological findings were orderly. At that time he complained of a headache, predominantly on the right side. He was directed to our clinic for suspicion of anterior arteritic ischemic optic neuropathy (AAION).

He was hyperopic (+3.5D OD and +2.0D OS), with additional presbyopia correction. He reported that 20 years prior, he suffered from headaches on the left side, resembling cluster headaches. His personal and family histories were unremarkable. On admission to our hospital, PCR for SARS-CoV-2 was repeated and it was negative. IgM and IgG antibodies remained positive.

Examination of his right fundus was notable for partial swelling of the optic nerve head and ganglion cell layer (Figure 1A). There was a relative afferent pupillary defect (RAPD). Other ocular fundus findings were normal bilaterally. His right eye was almost perimetrically blind, with visual field index (VFI) $1 \%$ and mean deviation (MD) $-31.56 \mathrm{~dB}$; the pattern deviation (PSD) was not shown for a severely depressed field, and left eye had also a sensitivity reduction: VFI of $90 \%$, MD -7.23 and PSD $1.86 \mathrm{~dB}$.

Serology tests were negative for Borrelia burgdorferi, human immunodeficiency virus, herpes simplex, varicella zoster, cytomegalovirus, Epstein-Barr virus and hepatitis $\mathrm{B}$ and $\mathrm{C}$ viruses. QuantiFERON gold test for tuberculosis was negative. Angiotensin-converting enzyme levels were within normal values. Antinuclear antibody (ANA), antineutrophil cytoplasmic antibodies (ANCA) and rheumatoid factor (RF) tests were within normal range, as were antiphospholipid and anticardiolipin antibodies. An aquaporin 4 (AQP4) antibody test was negative. The following were also normal: ESR, CRP, fibrinogen, D-dimer, coagulation times, ferritin and homocysteine. Plain chest and head radiographs revealed no abnormalities. The only suspicious result which arrived in the meantime was reactive result for Venereal Disease Research Laboratory (VDRL) test. We consulted an infectologist, and agreed with him to do Western blot for T. pallidum

He was treated only with pulse methylprednisolone therapy of $1000 \mathrm{mg}$ for five days in the clinic, with gastroprotection and glucose and blood pressure monitoring. On the fifth day of therapy his visual acuity was significantly better (20/63 or 0.3$)$, and visual field showed significant improvement (Figure 2A). The headache stopped during the first days of therapy.

Brain magnetic resonance imaging (MRI) was performed on the seventh day of hospitalization, in three planes with multiaxial reconstruction, before and after 
A

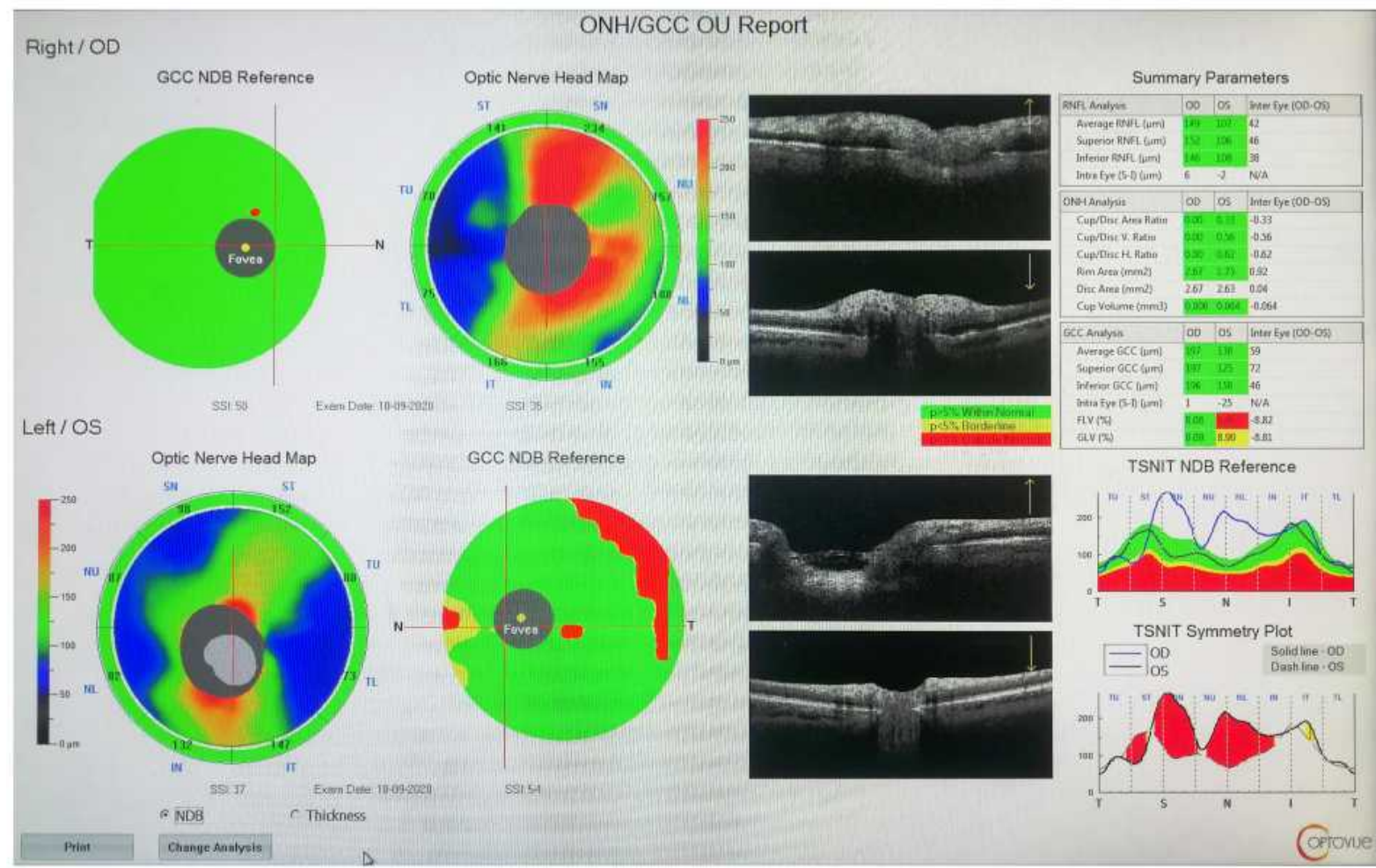

B

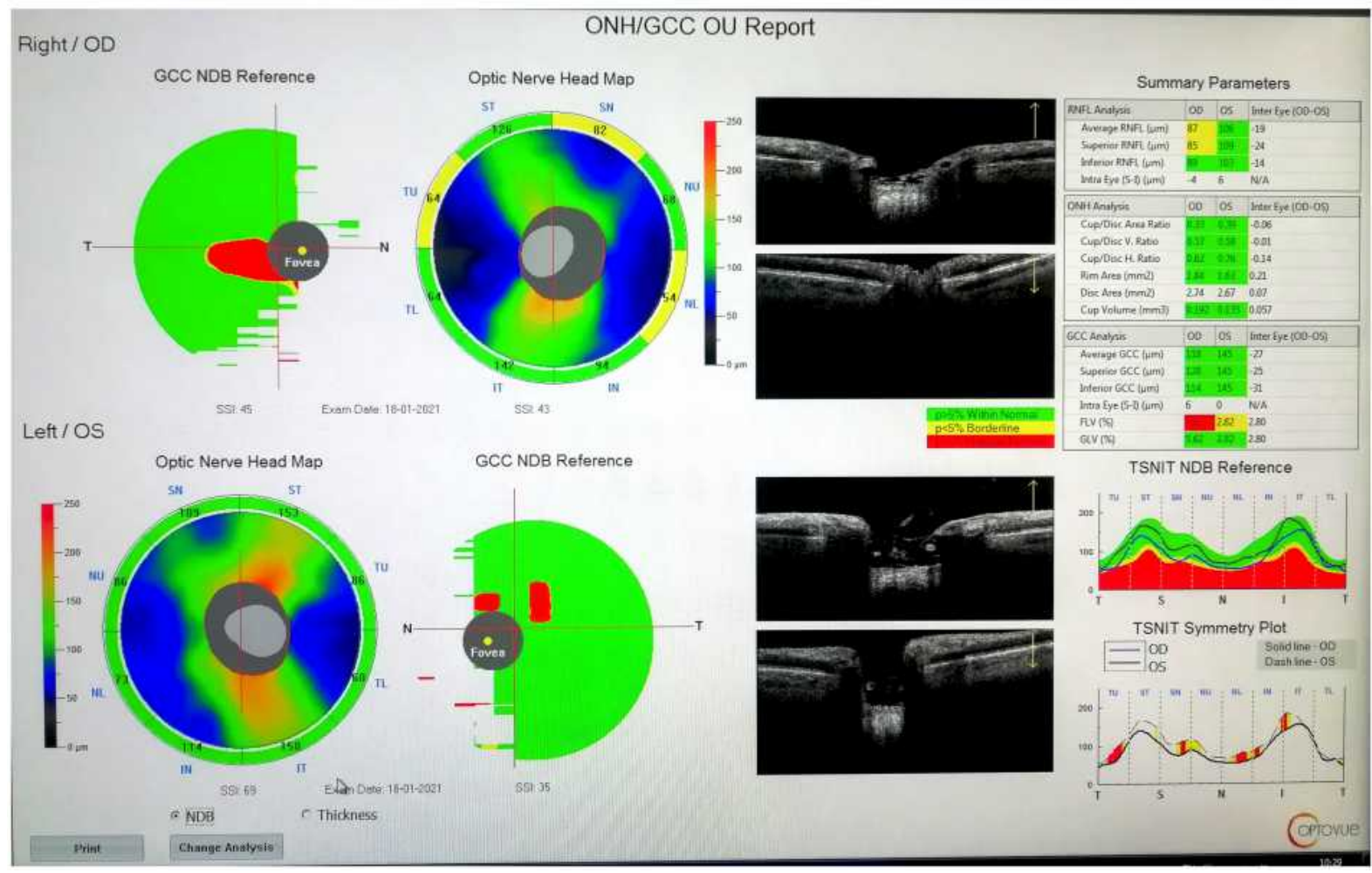

Figure I (A) Optic coherence tomography (OCT) of optic nerve head (OHN) shows edema of the right eye optic nerve head (OD), as thickening of retinal nerve fiber layer (RNFL) and ganglion cell complex (GCC) (given in Summary Parameters and temporal-superior-nasal-inferior-temporal (TSNIT) and on table and graphic on the right side of image). Values for the left eye (OS) are normal. (B) Four months after optic neuritis-the right eye optic disc edema is withdrawn and some atrophic changes appeared, most prominently in superior quadrant and as average thinning of RNFL (marked in yellow) and focal loss volume (FLV\%) (marked in red) on the right eye (OD), compared to the left eye (OS) normal values. 
A
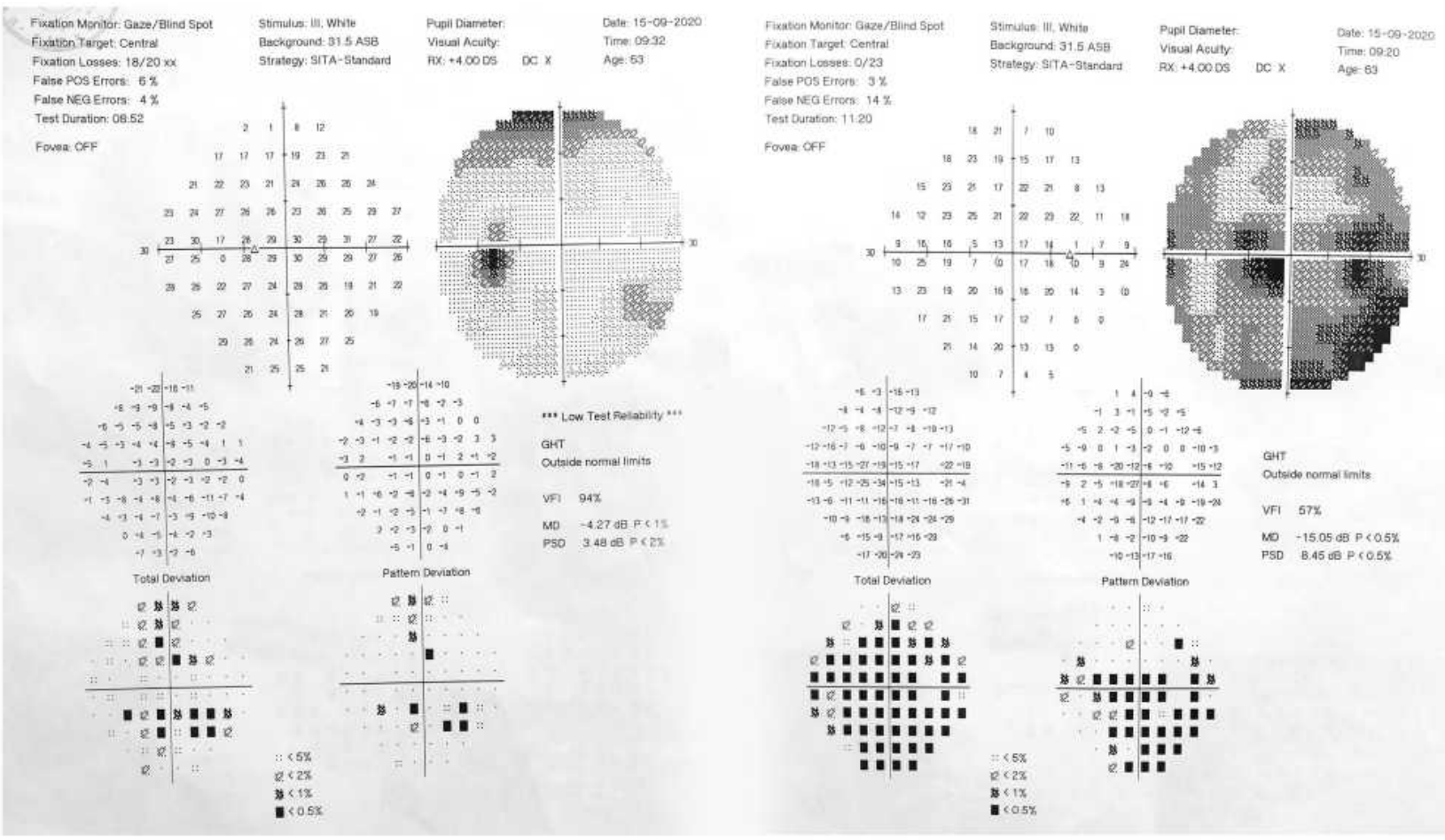

B

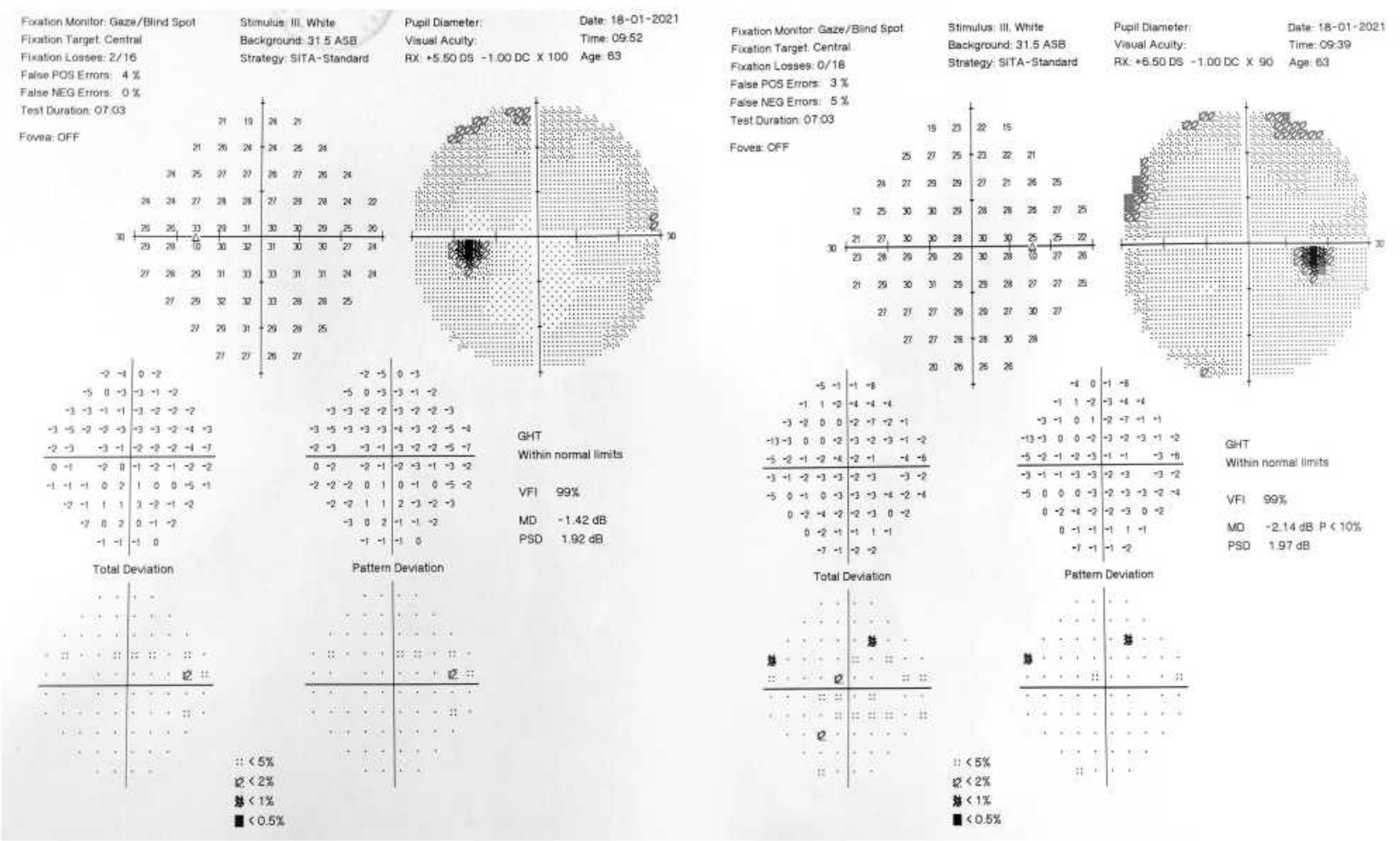

Figure 2 (A) Computed perimetry (visual field) at the end of pulse corticosteroid therapy-on the left eye (left side of figure) there is some sensitivity and pattern reduction (MD and PSD values); on the right eye (right side of figure) variables are still disturbed, but better than initial ones (described in the text): VFI 57\%, mean defect (MD) is halved $(-15.05 \mathrm{~dB})$ and pattern deviation (PSD) is now differentiated into scotomas. (B) normalization of visual field, four months later, with residual slight reduction of sensitivity on the right eye (right side of figure). 
the application of paramagnetic contrast. It revealed only microangiopathic and cortical reductive signs, a neuroglial cyst of $5 \mathrm{~mm}$ on the right temporal side, and normal appearing orbits and optic nerves. Spinal medulla on cervicothoracal contrast MRI was without significant alterations, with signs of spondyloarthrosis and hyperostosis.

After hospitalization, he was treated with prednisone tapering therapy for two weeks. On follow-up, three weeks later, he brought a Western blot tests for T. pallidum, which we ordered because of previous VDRL test result. The Western blot was negative for all antigenic bands for $\operatorname{IgG}$ and $\operatorname{IgM}$. We consulted a neurologist who did not identified any neurological disorders. His right visual acuity was 20/25 (0.8), and disk edema was resolved entirely. The left eye had normal functions. We ordered MOG antibodies, and two weeks later, we received positive result (titer 1:40, indirect immunofluorescence, cut off $1: 10)$.

At his final 3-month follow up, his visual acuity and computed visual field on the right eye were normal (VOD $20 / 20$ or 1.0; Figure $2 B$ ). The visual evoked potentials (3C PVEP) showed slightly prolonged latency of the p100 wave, and OCT suggested slight thinning of optic nerve fibers and ganglion cells, after optic neuritis (Figure 1B). The MOG antibodies titer was 1:20 and SARS-CoV-2 titers for IgM and IgG were 17.32 and 40.02, respectively.

\section{Discussion}

Isolated inflammation of the optic nerve in older adults is rare, especially in the form of unilateral papillitis. If optic neuritis manifests in an elderly, it is usually associated with systemic autoimmune or other granulomatous diseases, rather than previous viral illness. ${ }^{4}$ At the age of our patient, the diagnosis was more likely to be ischemic optic neuropathy than optic neuritis. However, his clinical course, laboratories findings and excellent therapeutic response suggest the diagnosis of optic neuritis, without other disorders, and most likely related to previous seropositive COVID-19 and MOG antibodies.

The exact role of MOG is unclear. It is thought to act as a cellular adhesive molecule, involved in regulating oligodendrocyte microtubule stability and to mediation of the complement cascade. ${ }^{10}$

MOG antibodies are associated with MOG-AD, a rare and specific group of demyelinating diseases. ${ }^{11,12}$ The clinical course can be monophasic or relapsing and usually has milder and more favorable clinical course than other demyelinating diseases. Optic neuritis may be the only manifestation. However, it most frequently manifests as AQP4-seronegative neuromyelitis optica, in adults in their 40 s or in combination with acute disseminated encephalomyelitis (ADEM), in children, or brainstem encephalitis. ${ }^{11,12}$

Although MOG-AD can occurs without any apparent inciting or predisposing cause, it has been found associated with post-infectious demyelination following infections with herpes simplex virus, Borrelia and Epstein-Barr virus. ${ }^{13-16}$ The prevailing mechanism of injury is felt to involve molecular mimicry, where a variety of potential viral antigens trigger an immune response directed toward endogenous CNS myelin proteins, including MOG. ${ }^{17}$

MOG antibodies can be found in serum. However, they do not cause nervous system disease until they cross the brain-blood barrier, usually due to inflammation or infection associated with elevated serum antibodies. ${ }^{18}$ Antibody synthesis occurs mostly extrathecally and cerebrospinal fluid testing is not usually required. MOG antibody titers are higher in relapse than in remission. In monophasic disease, decreasing titers are usually found. ${ }^{12,19}$

In experimental animals MOG antibodies are proven neuro-pathogenic factors, and disease can be provoked by coronaviruses. $^{20-23}$

Our patient is not the only one who demonstrated a connection between SARS-CoV-2 and MOG antibodies in the context of optic neuritis. ${ }^{5-8}$ Reports are scarce, which is understandable in the pandemic situation. Nevertheless, they are sufficient to be informative. Only one case was described following viral infection. ${ }^{7}$ Given the affinity of the virus to nervous tissues and cytokine storms during disease progression, the number of postinfectious cases should be higher.

Our patient was followed according to our current capabilities. Therefore, there are some limitations in our report.

Our patient was tested for MOG antibodies after completion of therapy. MOG antibodies in his serum were present. However, the titers were not very high. Therefore, we need to consider the possibility of the influence of immunosuppressive corticosteroid therapy on these titers. Two months after the first analysis, the titer remained positive, but was one-half of the previous value. This finding might suggest monophasic disease. Nevertheless, the follow-up period needed to be longer. Our patient had no signs of demyelinating disease on MRI, and the consulting neurologist found no other reasons to perform cerebrospinal fluid puncture and analysis. The 
only finding that suggests an autoimmune process was the MOG antibodies.

Our testing method involved immunohistochemistry, which requires serum titers above 1:10. Usually recommended method for MOG antibodies titer is the cell-based assay. $^{24}$ The patients in three previously mentioned cases had MOG antibodies. ${ }^{6-8}$ Not all authors reported the testing methods or titer levels. Only Sawalha et al reported serum titers in a man with bilateral optic neuritis, ${ }^{7}$ and Zhou et al in a man with optic neuritis and myelitis. ${ }^{6}$

The second limitation is that the PCR of the patient's nasopharyngeal swab was negative for SARS-CoV-2 negative three times, but antibodies, while $\operatorname{IgM}$ and IgG were positive. The presence of antibodies rises rapidly by the day 15 of onset of the disease, while RNA detectability declines between 15 and 39 days. $^{25}$ Despite exceptions that prove the rule, the most frequent sequence of virus-specific antibody conversion begins with an early IgM response, followed by a later emergence of IgG. These antibodies can appear synchronously and IgM can even appears after $\operatorname{IgG}^{26}$ The levels of IgG antibodies in our patient are high enough, several months after his first hospitalization, but it is similar for igM antibodies. Regarding PCR testing, bronchoalveolar lavage sample testing can be positive in cases with nasopharyngeal swab negative results. ${ }^{25,27}$

The consensus opinion is that diagnostic serology is of limited value, and PCR is preferred. Nevertheless, serology tests can be used for specific purposes such as for hospitalized patients with a suggestive clinical pictures and when there is a divergence between PCR and computed tomography findings. ${ }^{28}$

Our patient had bilateral bronchopneumonia, with laboratory results highly suspicious for COVID-19. It is, also, crucial to note that our patient was seropositive only for SARS-CoV-2, and not for other pathogens or diseases. Nevertheless, the viral antibodies titers were not monitored when his first hospitalization, and exact values of SARS-CoV -2 antibodies were only obtained at his final follow-up visit.

In our patient, and the three others reported with optic neuritis, ${ }^{6-8}$ COVID-19 infection presumably triggered an autoimmune response and the production of MOG antibodies. It is unclear whether the patients already had a predisposition to $\mathrm{MOG}$ associated disease, as in the described relapse of $\mathrm{MOG}-\mathrm{AD}$ in a patient during COVID- $19,{ }^{29}$ or if the virus set a novel process in motion.

\section{Conclusion}

Our patient had two still insufficiently clinically clarified conditions (COVID-19 and MOG-AD), which were possibly related in the form of post-infectious optic neuritis. Whether MOG antibodies play a pathogenic role in this and similar conditions, or whether they represent an incidental or additional effect (epiphenomenon), remain unclear. It is also questionable whether COVID-19 initiated his optic neuritis, or was merely a trigger for previously existing or predisposing non-recognized or subclinical disease. In any case, the COVID-19 pandemic provides new challenges, shedding light on and similar cases.

\section{Ethics}

Institutional approval was not required to publish the details of the case.

\section{Consent}

The patient has provided written informed consent for the case details and images to be published.

\section{Funding}

This research received no external funding.

\section{Disclosure}

The authors report no conflict of interest in this work.

\section{References}

1. Romero-Sánchez CM, Díaz-Maroto I, Fernández-Díaz E, et al. Neurologic manifestations in hospitalized patients with COVID-19: the ALBACOVID registry. Neurology. 2020;95(8):e1060-e1070. doi:10.1212/WNL.0000000000009937

2. Bertoli F, Veritti D, Danese C, et al. Ocular findings in COVID-19 patients: a review of direct manifestations and indirect effects on the eye. J Ophthalmol. 2020;2020:9 pages. Article ID 4827304. doi:10.1155/2020/4827304

3. Baig AM, Sanders EC. Potential neuroinvasive pathways of SARS-CoV-2: deciphering the spectrum of neurological deficit seen in coronavirus disease-2019 (COVID-19). J Med Virol. 2020;92 (10):1845-1857. PMID: 32492193; PMCID: PMC7300748. doi: $10.1002 / \mathrm{jmv} .26105$

4. Hoorbakht H, Bagherkashi F. Optic neuritis, its differential diagnosis and management. Open Ophthalmol J. 2012;6(1):65-72. PMID: 22888383; PMCID: PMC3414716. doi:10.2174/1874364101206010065

5. Gold DM, Galetta SL. Neuro-ophthalmologic complications of coronavirus disease 2019 (COVID-19). Neurosci Lett.2021;742:135531. PMID: 33248158; PMCID: PMC7687583. doi:10.1016/j.neulet.2020.135531

6. Zhou S, Jones-Lopez EC, Soneji DJ, Azevedo CJ, Patel VR. Myelin oligodendrocyte glycoprotein antibody-associated optic neuritis and myelitis in COVID-19. J Neuroophthalmol. 2020;40(3):398-402. doi:10.1097/WNO.0000000000001049 PMID: 32604245; PMCID: PMC7382408. 
7. Sawalha K, Adeodokun S, Kamoga GR. COVID-19-induced acute bilateral optic neuritis. J Investig Med High Impact Case Rep. 2020;8:2324709620976018. PMID: 33238757; PMCID: PMC7705770. doi:10.1177/2324709620976018

8. de Ruijter NS, Kramer G, Gons RAR, Hengstman GJD. Neuromyelitis optica spectrum disorder after presumed coronavirus (COVID-19) infection: a case report. Mult Scler Relat Disord.2020;46:102474. PMID: 32892062; PMCID: PMC7462544. doi:10.1016/j.msard.2020.102474

9. François J, Collery AS, Hayek G, et al. Coronavirus disease 2019 Associated ocular neuropathy with panuveitis: a case Report. JAMA Ophthalmol. 2021;139(2):247-249. doi:10.1001/jamaophthalmol.20 20.5695)

10. Wynford-Thomas R, Jacob A, Tomassini V. Neurological update: MOG antibody disease. J Neurol. 2019;266(5):1280-1286. [PMID 30569382; PMCID: PMC6469662]. doi:10.1007/s00415-018-9122-2

11. Pröbstel AK, Rudolf G, Dornmair K, et al. Anti-MOG antibodies are present in a subgroup of patients with a neuromyelitis optica phenotype. J Neuroinflammation. 2015;12(1):46. PMID: 25889963; PMCID: PMC4359547. doi:10.1186/s12974-015-0256-1

12. de Mol CL, Wong Y, van Pelt ED, et al. The clinical spectrum and incidence of anti-MOG-associated acquired demyelinating syndromes in children and adults. Mult Scler. 2020;26(7):806-814. PMID: 31094288; PMCID: PMC7294530. doi: 10.1177/ 1352458519845112

13. Vieira JP, Sequeira J, Brito MJ. Postinfectious anti-myelin oligodendrocyte glycoprotein antibody positive optic neuritis and myelitis. $J$ Child Neurol. 2017;32(12):996-999. PMID: 28820014. doi: $10.1177 / 0883073817724927$

14. Nakamura Y, Nakajima H, Tani H, et al. Anti-MOG antibody-positive ADEM following infectious mononucleosis due to a primary EBV infection: a case report. BMC Neurol. 2017;17(1):76. PMID: 28420330; PMCID: PMC5395865. doi:10.1186/s12883-017-0858-6

15. Nakamura M, Iwasaki Y, Takahashi T, et al. A case of MOG antibody-positive bilateral optic neuritis and meningoganglionitis following a genital herpes simplex virus infection. Mult Scler Relat Disord. 2017;17:148-150. PMID: 29055448. doi:10.1016/j. msard.2017.07.023

16. Kakalacheva K, Regenass S, Wiesmayr S, et al. Infectious mononucleosis triggers generation of igg auto-antibodies against native myelin oligodendrocyte glycoprotein.. Viruses. 2016;8(2):51. PMID: 26907324; PMCID: PMC4776206. doi:10.3390/v8020051

17. Barac-Latas V, Suchanek G, Breitschopf H, et al. Patterns of oligodendrocyte pathology in coronavirus-induced subacute demyelinating encephalomyelitis in the Lewis rat. Glia. 1997;19(1):1-12. doi:10.1002/(sici)1098-1136(199701)19:1<1::aid-glia1>3.0.co;2-5.

18. Reindl M, Waters P. Myelin oligodendrocyte glycoprotein antibodies in neurological disease. Nat Rev Neurol. 2019;15(2):89-102. PMID: 30559466. doi:10.1038/s41582-018-0112-x
19. Cobo-Calvo A, Ruiz A, Maillart E, et al. OFSEP and NOMADMUS Study Group. Clinical spectrum and prognostic value of CNS MOG autoimmunity in adults: the MOGADOR study. Neurology. 2018;90 (21):e1858-e1869. PMID: 29695592. doi: 10.1212 WNL.0000000000005560

20. Peschl P, Bradl M, Höftberger R, Berger T, Reindl M. Myelin oligodendrocyte glycoprotein: deciphering a target in inflammatory demyelinating diseases. Front Immunol. 2017;8:529. PMID: 28533781; PMCID: PMC5420591. doi:10.3389/fimmu.2017.00529

21. Wege H, Schluesener H, Meyermann R, Barac-Latas V, Suchanek G, Lassmann H. Coronavirus infection and demyelination. Development of inflammatory lesions in Lewis rats. Adv Exp Med Biol. 1998;440:437-444. PMID: 9782312.

22. Wu Y, Xu X, Chen $\mathrm{Z}$, et al. Nervous system involvement after infection with COVID-19 and other coronaviruses. Brain Behav Immun.2020;87:18-22. PMID: 32240762; PMCID: PMC7146689. doi:10.1016/j.bbi.2020.03.031

23. Shindler KS, Kenyon LC, Dutt M, Hingley ST, Das Sarma J. Experimental optic neuritis induced by a demyelinating strain of mouse hepatitis virus. J Virol. 2008;82(17):8882-8886. PMID: 18579591; PMCID: PMC2519666. doi:10.1128/JVI.00920-08

24. Jarius S, Paul F, Aktas O, et al. MOG encephalomyelitis: international recommendations on diagnosis and antibody testing. J Neuroinflammation. 2018;15(1):134. PMID: 29724224; PMCID: PMC5932838. doi:10.1186/s12974-018-1144-2

25. Zhao J, Yuan Q, Wang H, et al. Antibody Responses to SARS-CoV-2 in patients with novel coronavirus disease 2019. Clin Infect Dis. 2020;71(16):2027-2034. doi:10.1093/cid/ciaa344 PMID: 32221519; PMCID: PMC7184337.

26. Long QX, Liu BZ, Deng HJ, et al. Antibody responses to SARS-CoV-2 in patients with COVID-19. Nat Med. 2020;26 (6):845-848. doi:10.1038/s41591-020-0897-1

27. Little BP. False-negative nasopharyngeal swabs and positive bronchoalveolar lavage: implications for chest $\mathrm{CT}$ in diagnosis of COVID-19 Pneumonia. Radiology. doi:10.1148/radiol.2020204471.

28. Chuen V, Said H, Shell J, Plaxton W, Ciccotelli W. Diagnosis of COVID-19 by bronchoalveolar lavage after two negative nasopharyngeal swabs. Can J Gen Intern Med. 2020;15(2):5-7. doi:10.22374/ cjgim.v15i2.449

29. Woodhall M, Mitchell JW, Gibbons E, Healy S, Waters P, Huda S. Case Report: myelin oligodendrocyte glycoprotein antibody-associated relapse with COVID-19. Front Neurol. 2020;11:598531. PMID: 33324337; PMCID: PMC7724101 doi:10.3389/fneur.2020.598531
International Medical Case Reports Journal

\section{Publish your work in this journal}

The International Medical Case Reports Journal is an international, peer-reviewed open-access journal publishing original case reports from all medical specialties. Previously unpublished medical posters are also accepted relating to any area of clinical or preclinical science. Submissions should not normally exceed 2,000 words or 4 published pages including figures, diagrams and references. The manuscript management system is completely online and includes a very quick and fair peer-review system, which is all easy to use. Visit http://www.dovepress.com/testimonials.php to read real quotes from published authors. 